Arnaldo Dubin

Mario Omar Pozo

Gonzalo Ferrara

Gastón Murias

Enrique Martins

Carlos Canullán

Héctor Saul Canales

Vanina Siham Kanoore Edul

Elisa Estenssoro

Can Ince

\section{Systemic and microcirculatory responses to progressive hemorrhage}

Received: 8 March 2008

Accepted: 10 December 2008

Published online: 6 January 2009

(C) Springer-Verlag 2008

This article is discussed in the editorial available at:

doi:10.1007/s00134-008-1386-z.

Electronic supplementary material The online version of this article (doi:10.1007/s00134-008-1385-0) contains supplementary material, which is available to authorized users.

\author{
A. Dubin - M. O. Pozo - G. Ferrara . \\ G. Murias - E. Martins - C. Canullán · \\ H. S. Canales · V. S. Kanoore Edul . \\ E. Estenssoro \\ Cátedra de Farmacología Aplicada, \\ Facultad de Ciencias Médicas, \\ Universidad Nacional de La Plata, \\ La Plata, Argentina \\ C. Ince \\ Translational Physiology, \\ Academic Medical Center, \\ University of Amsterdam, \\ Amsterdam, The Netherlands
}

A. Dubin (汭)

calle 42 No. 577, 1900 La Plata, Argentina e-mail: arnaldodubin@speedy.com.ar Tel.: +54-221-4220507

Abstract Objective: To compare
systemic hemodynamics with micro-
circulatory changes at different
vascular beds during progressive
hemorrhage. Setting: University-
based research laboratory.
Subjects: Twelve anesthetized,
mechanically ventilated sheep. Inter-
ventions: Sheep were randomly
assigned to HEMORRHAGE or
CONTROL group. In the HEMOR-
RHAGE group ( $n=8$ ), three
stepwise bleedings of 5 ml/kg at $30-$
min intervals were performed to add
up 15 ml/kg. In the CONTROL group
( $n=4$ ), sheep had the same surgical
preparation but were not bled.
Measurements and main
results: Progressive bleeding
decreased cardiac output, and supe-
rior mesenteric artery blood flow, and
systemic and intestinal oxygen trans-
ports from the first step of bleeding
whereas systemic and intestinal oxy-
gen consumption remained

unchanged. Mean arterial blood pressure, arterial $\mathrm{pH}$ and base excess, and intramucosal-arterial $P \mathrm{CO}_{2}$ were only significantly modified in the last step of bleeding. Arterial lactate increased and sublingual, and intestinal serosal and mucosal capillary microvascular flow indexes and red blood cell velocities progressively decreased after the first step of bleeding (3.0 \pm 0.1 vs. $2.3 \pm 0.4$, $3.2 \pm 0.2$ vs. $2.4 \pm 0.6,3.0 \pm 0.0$ vs. $2.0 \pm 0.2$, and $1,082 \pm 29$ vs.

$977 \pm 79,1,042 \pm 24$ vs. $953 \pm 60$, $287 \pm 65$ vs. $262 \pm 16 \mu \mathrm{m} / \mathrm{s}$; $P<0.05$ for all).

Conclusions: Alterations in sublingual, intestinal microcirculation, and arterial lactate simultaneously arose from the first step of bleeding. The microcirculatory changes were identified either by semi-quantitative flow index or by quantitative red blood cell velocity measurements.

Keywords Oxygen transport . Blood flow · Hemorrhage . Microcirculation · Intramucosal acidosis · Lactate

\section{Introduction}

The outcome of shock is related to the magnitude of acquired oxygen debt [1], as well as to delays in treatment [2]. Indeed, the availability of diagnostic approaches for the early identification of tissue hypoperfusion is crucial.
Different parameters such as gastric tonomety [3], sublingual capnometry [4], arterial lactate [5], venous oxygen saturation [2], and base excess [6] have been used to track changes in intravascular volume.

The monitoring of microcirculation may be helpful for this goal. The direct evaluation of microvascular 
oxygenation gives more comprehensive information than the $\mathrm{PO}_{2}$ in the venous effluent. Sinaasappel et al. [7] showed an increase in the gradient between microvascular and venous $P_{2}$, during hemorrhagic shock in the pig intestine, suggesting the occurrence of functional shunting of the microcirculation. Application of various techniques including intravital microscopy has shown the presence of microcirculatory alterations during hemorrhage. These alterations include reduced flow and arteriolar diameter in the intestinal villi [8,9], muscle [10], and skin [11]; altered visualization of the villi vascular network [12]; decreased buccal capillary flow [13]; and increased leukocyte rolling and adhesion in the mesenteric microcirculation [14]. In addition, Kerger et al. [15] have shown in an experimental model of hemorrhagic shock and resuscitation that the impairment of functional capillary density is the main determinant of outcome. Nevertheless, due to technical limitations, the use of these methods has been restricted to basic research. Conversely, the development of orthogonal polarization spectrum (OPS) and more recently sidestream dark-field (SDF) imaging [16] allow clinicians to directly visualize and monitor the microcirculation in critically ill patients $[17,18]$.

Although different microvascular derangements have been identified in hemorrhagic shock, no study has focused on less severe degrees of hypovolemia, either in patients or in clinically relevant animal models. Furthermore, there were no reports, in this setting, about the simultaneous behavior of microcirculation in different vascular beds and their relationship with systemic blood flow. Our goal was to assess the behavior of sublingual and serosal and mucosal intestinal microcirculation, during a stepwise bleeding. Particularly, this study was designed to compare the sequential changes of microcirculation with other variables commonly used in the diagnosis and monitoring of shock. Our main hypothesis in this study was that microcirculatory alterations developed in different organs and their compartments simultaneously. A second hypothesis we wished to test was whether microvascular changes as measured by an easy to implement semi-quantitative microvascular flow index (MFI) [19] could be used to identify hypovolemia. This work has been previously presented in abstract form [20].

\section{Materials and methods}

Additional details are provided in the electronic supplementary material (ESM).

\section{Surgical preparation}

Fourteen sheep $(25 \pm 5 \mathrm{~kg})$ were anesthetized with $30 \mathrm{mg} / \mathrm{kg}$ of sodium pentobarbital, intubated and mechanically ventilated. Neuromuscular blockade was performed with intravenous pancuronium bromide $(0.06 \mathrm{mg} / \mathrm{kg})$. Additional pentobarbital boluses [1 mg/ $(\mathrm{kg} \mathrm{h})$ ] were administered as required. Analgesia was provided by fentanyl as a bolus of $2 \mu \mathrm{g} / \mathrm{kg}$ followed by $1 \mu \mathrm{g} /(\mathrm{kg} \mathrm{h})$.

Catheters were advanced through left femoral vein to administer fluids and drugs, and through left femoral artery to measure blood pressure and to obtain blood samples. A pulmonary artery catheter was inserted through right external jugular vein.

A midline laparotomy was performed followed by a gastrostomy to allow drainage of gastric contents, and a splenectomy. An electromagnetic flow probe was placed around the superior mesenteric artery (SMA). A catheter was placed in the mesenteric vein through a small vein proximal to the gut to draw blood samples. A tonometer was inserted through a small ileotomy to measure intramucosal $P \mathrm{CO}_{2}$. A 10 - to $15-\mathrm{cm}$ segment of the ileum was mobilized, placed outside the abdomen, and opened $2 \mathrm{~cm}$ on its antimesenteric border to allow the examination of the mucosa. The exteriorized intestinal segment was covered, and moisture and temperature were preserved by a device. Finally, after careful hemostasis, the abdominal wall incision was closed, leaving a short segment for externalization of the ileal loop.

\section{Measurements and derived calculations}

Arterial, pulmonary, and central venous pressures (CVP) were measured with corresponding transducers. Cardiac output was measured in triplicate and normalized to body weight. SMA blood flow was measured by the electromagnetic method and normalized to gut weight.

Arterial, mixed venous, and mesenteric venous $\mathrm{PO}_{2}$, $P_{C O}$, and $\mathrm{pH}$ were measured with a blood gas analyzer, and hemoglobin and oxygen saturation were measured with a cooximeter. Systemic and intestinal oxygen transports and consumptions $\left(\mathrm{DO}_{2}\right.$ and $\left.\mathrm{VO}_{2}\right)$ were calculated by standard equations.

Intramucosal $\mathrm{PCO}_{2}$ was measured with a tonometer using an automated air tonometry system. Its value was used to calculate $\triangle P \mathrm{CO}_{2}$. Arterial lactate was measured with an electrode.

\section{Microcirculatory measurements and analysis}

The microcirculatory network was evaluated in the sublingual mucosa and the intestinal mucosa and serosa using a SDF-imaging device (Microscan ${ }^{\circledR}$, MicroVision Medical, Amsterdam, The Netherlands) [16]. After gentle removal of saliva/faeces, steady images of at least $20 \mathrm{~s}$ were obtained, avoiding pressure artifacts, using a portable computer and an analog/digital video converser. Each 
image was divided into four equal quadrants. Adequate focus and contrast adjustments were verified. Images of poor quality were discarded (19\% of stored videos).

Video clips were analyzed blindly and randomly using two approaches. First, we used a modification of a semiquantitative score [19]. It distinguishes no flow (0), intermittent flow [1], sluggish flow [2], continuous flow [3], and hyperdynamic blood flow [4]. The overall score, called MFI, is the sum of each quadrant-score divided by the number of quadrants in which the vessel type is visible [19]. For each animal, values obtained from three fields were averaged.

Image analysis software developed for the SDF video images (Microscan analysis software ${ }^{\circledR}$ (MAS 2.0), MicroVision Medical, Amsterdam, The Netherlands) was used to generate so-called "space-time diagrams" of single vessel for quantitative measurement of red blood cell velocity (RBCV) [21]. In addition, vascular density (expressed as \% of baseline) was measured.

To determine heterogeneity of perfusion in each territory, the flow heterogeneity index was calculated as the highest MFI minus the lowest MFI divided by the mean MFI [22]. In addition, the coefficient of variation (CV) of RBCVs was calculated [17].

In the sheep studied, most of sublingual and ileal serosal vascular density ( $97 \pm 1 \%$ of total vessel length), and all villi vessels consisted of capillaries (diameter below $20 \mu \mathrm{m}$ ) [23], so the analysis was focused on these vessels.

\section{Experimental procedure}

Basal measurements were taken after a stabilization period of no less than $30 \mathrm{~min}$. After basal measurements, sheep were randomly assigned to either HEMORRHAGE or CONTROL group. In the HEMORRHAGE group $(n=8)$, three stepwise bleedings of $5 \mathrm{ml} / \mathrm{kg}$ at $30-\mathrm{min}$ intervals were performed to add up $15 \mathrm{ml} / \mathrm{kg}$. In the CONTROL group $(n=4)$, sheep had the same surgical preparation but were not bled. Measurements were recorded at the end of each step of bleeding.

At the end of the experiment, the animals were euthanized with an additional dose of pentobarbital and a potassium chloride bolus.

Care of animals was in accordance with National Institute of Health guidelines.

\section{Statistical analysis}

Data were assessed for normality and expressed as mean \pm standard deviation (SD). Two-way repeated measures ANOVA was used. When significant time $\times-$ group or time effect were observed, Student-NewmanKeuls or Dunnett's tests were applied. The $P$ value $<0.05$ was considered to be significant. Spearman rank correlation coefficients between MFIs and RBCVs were calculated.

\section{Results}

Hemodynamic and oxygen transport variables

In the HEMORRHAGE group, cardiac output, SMA blood flow, and systemic and intestinal $D_{2}$ progressively decreased following bleeding. The systemic and intestinal $V \mathrm{O}_{2}$, however, remained unchanged. Mean arterial blood pressure was significantly reduced only in the last step of bleeding. CVP, pulmonary artery occlusion pressure (PAOP), and heart rate did not change. In the CONTROL group, all these variables were unchanged (Table 1 in ESM).

Acid-base metabolism

Arterial $\mathrm{pH}$ and base excess decreased only in the last phase of hemorrhage (Table 2 in ESM and Fig. 1). These variables remained unchanged in the CONTROL group.

\section{Arterial lactate and $\triangle P C \mathrm{O}_{2}$}

Arterial lactate had progressive and significant increases already in the first stage of bleeding, $\triangle P \mathrm{CO}_{2}$ significantly increased only in the final step (Fig. 1).

\section{Microcirculation}

Typical videos of the different microcirculatory beds, as well as a space-time diagram used to calculate RBCV are shown in ESM. RBCV measurements were more frequently feasible in sublingual and ileal serosal than in ileal mucosal sites (Table 1).

From the initial period of bleeding, a stepwise decrease in sublingual, and ileal serosal and mucosal MFIs, and RBCVs was observed in the HEMORRHAGE group. These values remained unchanged in the control group (Fig. 2).

The percent of baseline values for sublingual, and ileal serosal and mucosal RBCVs was similar (17 \pm 5 , $22 \pm 11$, and $16 \pm 12 \%, P=\mathrm{NS}$ ) (Fig. 3). Capillary densities were progressively reduced in ileal and sublingual mucosa, but the decrease was not statistically significant in ileal serosa. The reduction was higher in ileal mucosa $(63 \pm 11,73 \pm 22$, and $55 \pm 2 \%, P<0.05)$ (Fig. 4).

Heterogeneity flow index increased in the three territories, but it was more impaired in ileal mucosa than in ileal serosa and sublingual mucosa $(0.66 \pm 0.38$, 

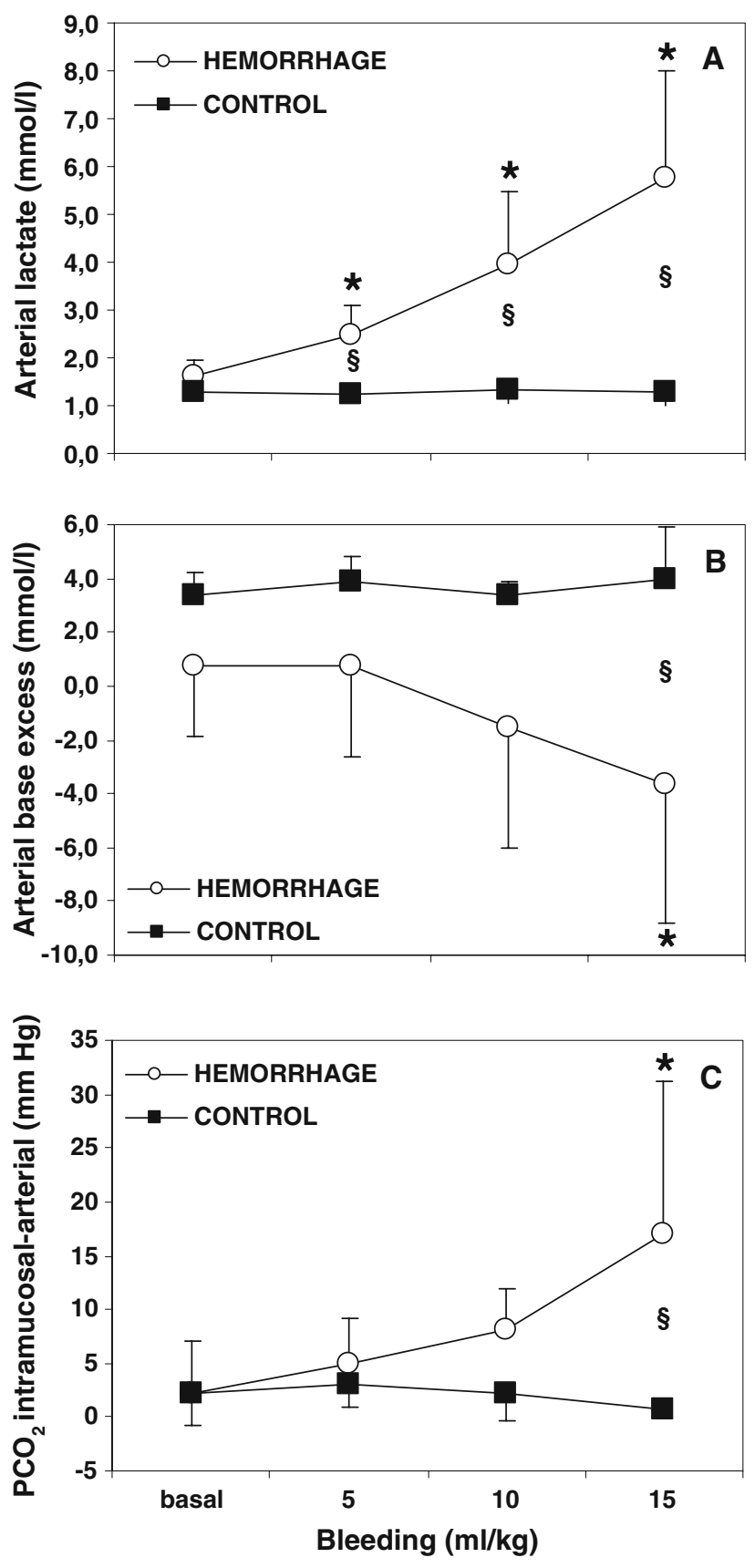

Fig. 1 Behaviour of arterial lactate (a), arterial base excess (b) and ileal intramucosal-arterial $\mathrm{PCO}_{2}$ gradient (c) in HEMORRHAGE and CONTROL groups. Bars are standard deviations. ${ }^{*} P<0.05$ versus basal, and $\S P<0.05$ versus CONTROL group, after twoway repeated measures ANOVA significant time $\times$ group effect

$0.25 \pm 0.16$, and $0.15 \pm 0.07, P<0.05$ ) (Fig. 2 in ESM). CVs of RBCVs were only significantly modified in ileal mucosa (Fig. 3 in ESM). RBCV histograms of typical experiments are shown in ESM (Figs. 4, 5, 6).

There were significant correlations between sublingual, and ileal serosal and mucosal MFIs, and the
Table 1 Number of analyzed vessels and percentage of vessels in which the measurement of red blood cell velocity was possible

\begin{tabular}{|c|c|c|c|}
\hline \multirow[t]{2}{*}{ Group } & \multicolumn{2}{|c|}{$\begin{array}{l}\text { Number of analyzed } \\
\text { vessels }\end{array}$} & \multirow{2}{*}{$\begin{array}{l}\text { Vessels in which } \\
\text { measurement } \\
\text { was possible } \\
\text { Mean } \% \pm \mathrm{SD}\end{array}$} \\
\hline & Mean $\pm \mathrm{SD}$ & Median [25-75] & \\
\hline \multicolumn{4}{|c|}{ Sublingual mисоsa } \\
\hline \multicolumn{4}{|l|}{ Basal } \\
\hline Hemorrhage & $62 \pm 7$ & 63 [59-65] & $78 \pm 4$ \\
\hline Control & $62 \pm 6$ & $69[66-72]$ & $78 \pm 6$ \\
\hline \multicolumn{4}{|l|}{$5 \mathrm{ml} / \mathrm{kg}$} \\
\hline Hemorrhage & $59 \pm 9$ & $59[51-66]$ & $71 \pm 1$ \\
\hline Control & $60 \pm 7$ & $68[63-71]$ & $71 \pm 9$ \\
\hline \multicolumn{4}{|l|}{$10 \mathrm{ml} / \mathrm{kg}$} \\
\hline Hemorrhage & $56 \pm 9$ & 59 [49-63] & $70 \pm 5$ \\
\hline Control & $51 \pm 3$ & 53 [51-55] & $69 \pm 2$ \\
\hline \multicolumn{4}{|l|}{$15 \mathrm{ml} / \mathrm{kg}$} \\
\hline Hemorrhage & $52 \pm 12$ & 52 [41-61] & $66 \pm 9$ \\
\hline Control & $52 \pm 15$ & $54[50-66]$ & $66 \pm 6$ \\
\hline \multicolumn{4}{|l|}{ Ileal serosa } \\
\hline \multicolumn{4}{|l|}{ Basal } \\
\hline Hemorrhage & $41 \pm 4$ & $41[38-45]$ & $61 \pm 7$ \\
\hline Control & $39 \pm 4$ & $40[41-45]$ & $61 \pm 7$ \\
\hline \multicolumn{4}{|l|}{$5 \mathrm{ml} / \mathrm{kg}$} \\
\hline Hemorrhage & $38 \pm 6$ & 33 [38-42] & $56 \pm 9$ \\
\hline Control & $37 \pm 4$ & 38 [41-42] & $56 \pm 10$ \\
\hline \multicolumn{4}{|l|}{$10 \mathrm{ml} / \mathrm{kg}$} \\
\hline Hemorrhage & $35 \pm 4$ & 33 [35-39] & $54 \pm 7$ \\
\hline Control & $35 \pm 5$ & $35[36-39]$ & $55 \pm 9$ \\
\hline \multicolumn{4}{|l|}{$15 \mathrm{ml} / \mathrm{kg}$} \\
\hline Hemorrhage & $36 \pm 7$ & 29 [33-35] & $52 \pm 9$ \\
\hline Control & $36 \pm 6$ & $31[34-41]$ & $53 \pm 13$ \\
\hline \multicolumn{4}{|l|}{ Ileal mucosa } \\
\hline \multicolumn{4}{|l|}{ Basal } \\
\hline Hemorrhage & $12 \pm 3$ & 13 [10-13] & $32 \pm 13$ \\
\hline Control & $10 \pm 2$ & $10[10-10]$ & $28 \pm 7$ \\
\hline \multicolumn{4}{|l|}{$5 \mathrm{ml} / \mathrm{kg}$} \\
\hline Hemorrhage & $9 \pm 3$ & 9 [7-10] & $34 \pm 17$ \\
\hline Control & $9 \pm 2$ & 9 [8-10] & $28 \pm 3$ \\
\hline \multicolumn{4}{|l|}{$10 \mathrm{ml} / \mathrm{kg}$} \\
\hline Hemorrhage & $9 \pm 2$ & 8 [7-11] & $32 \pm 15$ \\
\hline Control & $9 \pm 2$ & $10[7-11]$ & $31 \pm 15$ \\
\hline \multicolumn{4}{|l|}{$15 \mathrm{ml} / \mathrm{kg}$} \\
\hline Hemorrhage & $9 \pm 2$ & 9 [8-10] & $28 \pm 8$ \\
\hline Control & $9 \pm 2$ & 9 [8-11] & $26 \pm 8$ \\
\hline
\end{tabular}

corresponding RBCVs (Fig. 5). However this correlation was less evident in the mucosal microcirculation.

MFIs and RBCVs were significantly correlated with lactate and $\triangle \mathrm{PCO}_{2}$ (Figs. 7 and 8 in ESM).

\section{Discussion}

The main finding of the present study is that sublingual and intestinal microcirculation becomes progressively impaired during bleeding. These microcirculatory changes might be measured by either a semi-quantitative flow score or by direct measurement. This study suggests that the monitoring of the microcirculation may be a useful measure of hypovolemia. 
Fig. 2 During stepwise bleeding, there were progressive decreases of sublingual (a), ileal serosal (b), and ileal mucosal (c) microvascular flow indexes, and sublingual (d), ileal serosal (e), and ileal mucosal (f) capillary red blood cell velocities (RBCV) in HEMORRHAGE group. These variables remained unchanged in CONTROL group. RBCV was only measured in vessels with continuous flow. It was not possible in vessels with intermittent or absent flow. Bars are standard deviations. $* P<0.05$ versus basal, and $\S P<0.05$ versus CONTROL group, after two-way repeated measures ANOVA significant time $\times$ group effect
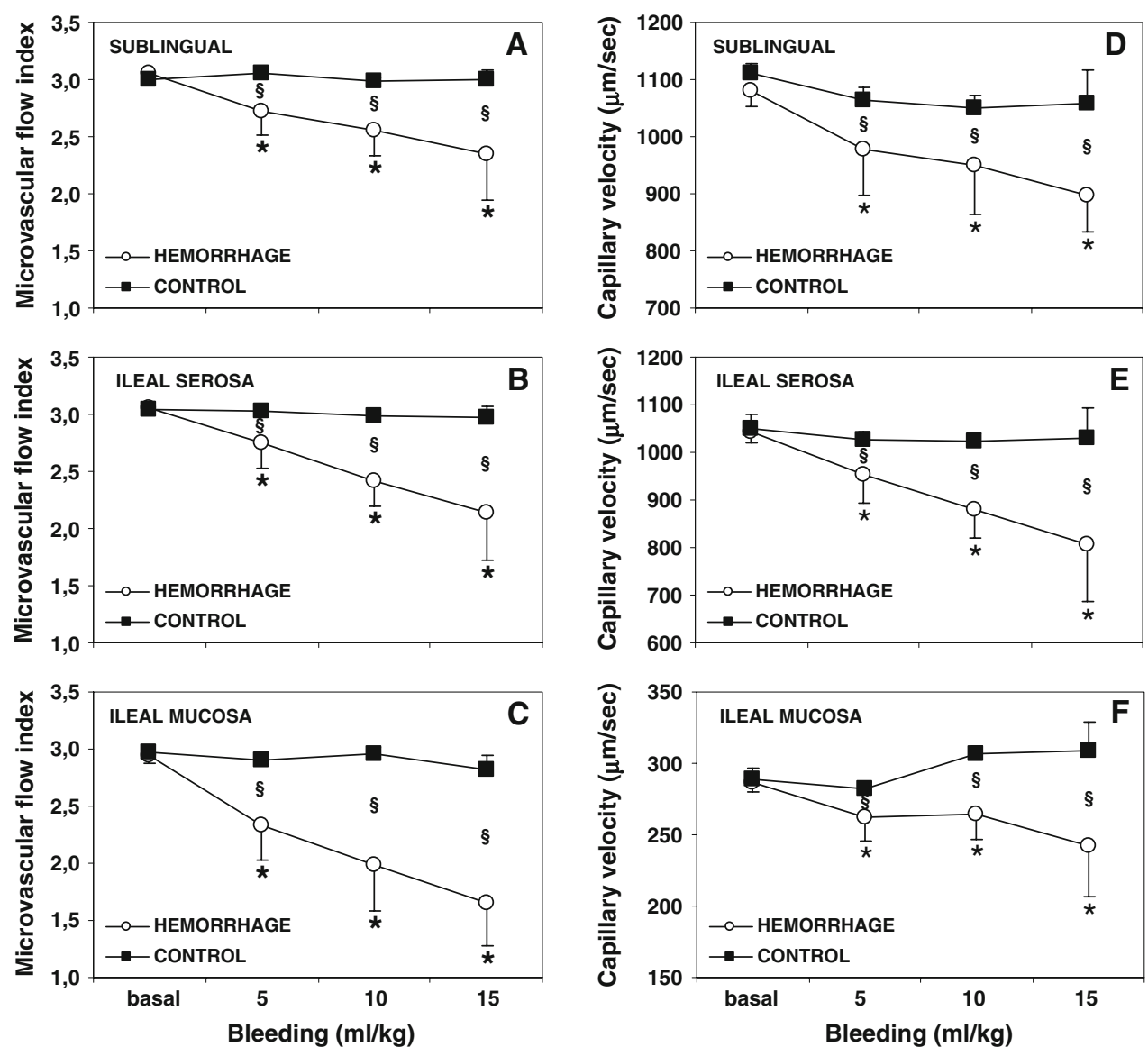

Since our goal was to study the behavior of microcirculation at different territories and its relationship with systemic hemodynamics and other currently used parameters, we performed a progressive stepwise bleeding. Given that intravascular volume of sheep is about $60 \mathrm{ml} / \mathrm{kg}$ [24], the first bleeding corresponded to about $8 \%$ of volemia (probably smaller than a grade I hemorrhage) [25]. Nevertheless, cardiac output decreased $24 \%$ showing a high susceptibility of this model to bleeding. Accordingly to previous reports [26], mean arterial blood pressure was only decreased when the blood loss was close to $25 \%$ of the volemia. CVP and PAOP, however, remained unchanged.

Semi-quantitative and quantitative methods were used for the evaluation of microcirculatory changes. These showed significant and parallel changes in the three locations from the first stage of hemorrhage onwards. The semi-quantitative method used in this study was the MFI score [19], developed and applied for identifying microcirculatory alterations in sepsis $[22,27,28]$. Its main advantages are that it is relatively simple to determine and takes into account the fact that flow can be continuous but very slow (sluggish). The reproducibility of this approach has been recently demonstrated [19, 22]. Nevertheless, this score does not provide information about functional capillary density [23]. The excellent performance of MFI in this model of hypovolemia does not imply that MFI can be used for identifying microcirculatory alterations in other disease states where the microcirculation is compromised. Each disease state may bring its own characteristic scoring method.

The MFI index correlated with quantitatively measured RBCV in individual capillaries. RBCV was determined using space-time diagrams obtained by automatically tiling the centerline intensity of a vessel as vertical lines for a number of consecutive frames [21]. The good correlation between MFI and RBCV changes during progressive bleeding validates the possible use of the MFI as an index of hypovolemia, at least in the conditions of global hypoperfusion. Indeed, Deruddre et al. [29] recently used sublingual SDF images to titrate volume loading in a clinical study.

The percent reductions of RBCV were lesser than those of cardiac output. A possible explanation is that microcirculatory changes, at least in the studied territories, are only adjustments driven by cardiac output. Conversely, drops in RBCVs went along with diminished vascular density and increased heterogeneity. Consequently, the 

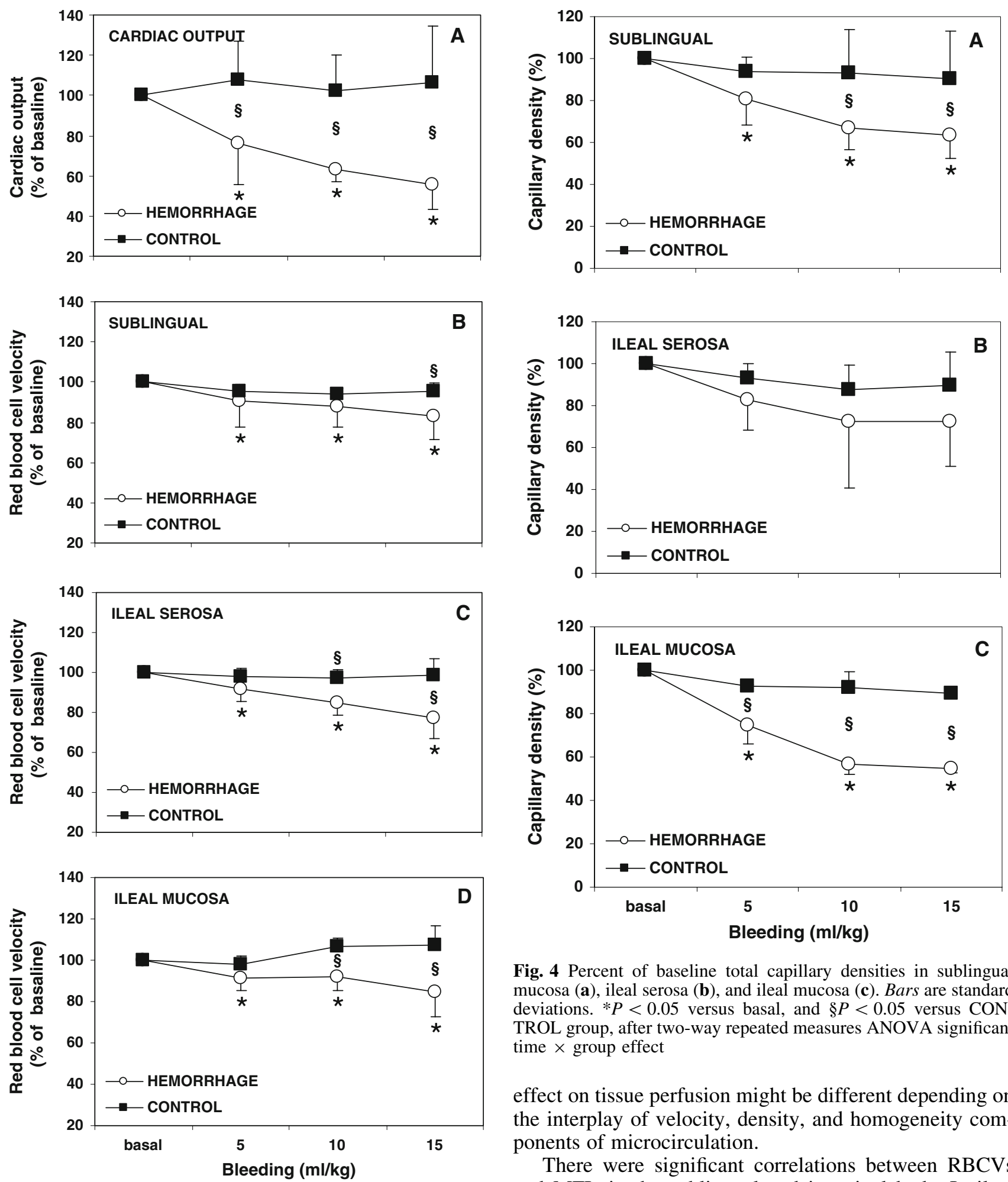

Fig. 3 Percent of baseline cardiac output (a), sublingual (b), ileal serosal (c), and ileal mucosal (d) red blood cell velocities. Bars are standard deviations. $* P<0.05$ versus basal, and $\S P<0.05$ versus CONTROL group, after two-way repeated measures ANOVA significant time $\times$ group effect

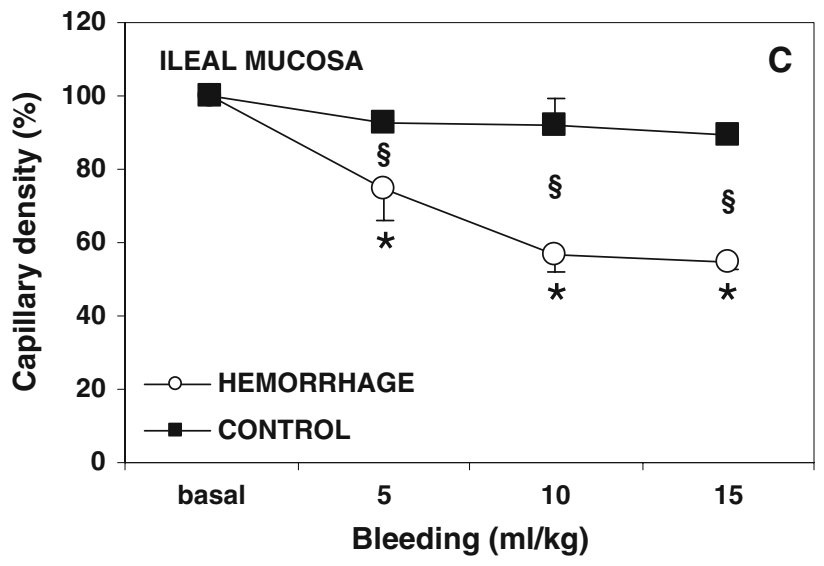

Fig. 4 Percent of baseline total capillary densities in sublingual mucosa (a), ileal serosa (b), and ileal mucosa (c). Bars are standard deviations. ${ }^{*} P<0.05$ versus basal, and $\$ P<0.05$ versus $\mathrm{CON}-$ TROL group, after two-way repeated measures ANOVA significant time $\times$ group effect

effect on tissue perfusion might be different depending on the interplay of velocity, density, and homogeneity components of microcirculation.

There were significant correlations between RBCVs and MFIs in the sublingual and intestinal beds. In ileal mucosa, however, the correlation was weaker. Technical reasons might underlie this finding. In sublingual mucosa and ileal serosa, it was possible to measure RBCV in most of the vessels. For the mucosa, however, the complex 

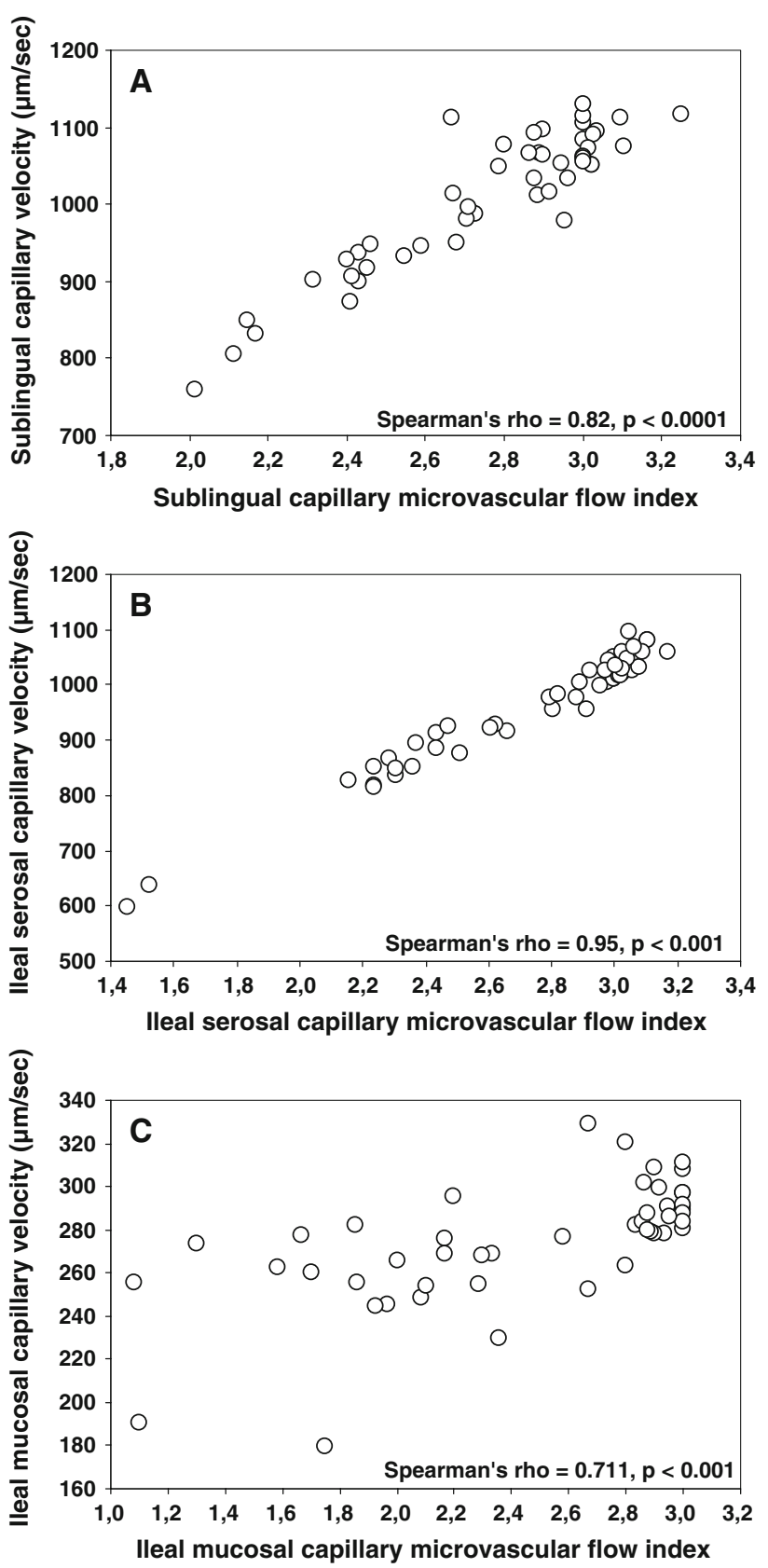

Fig. 5 Correlations between sublingual (a), ileal serosal (b), and ileal mucosal (c) microvascular flow indexes and red blood cell velocities. RBCV was only measured in vessels with continuous flow. It was not possible in vessels with intermittent or absent flow

anatomic characteristics of the microvascular network of the villi only allowed measurement of a limited number of capillaries. Bifurcations cause a change in RBCV so that for a reliable assessment, space-time diagrams have to be determined from a long enough vessel segment between bifurcations. In addition, periodic fluctuations were found to occur in capillary blood flow, an affect described previously for hemorrhagic shock [30], and this introduced inaccuracies in the determination of villi RBCV.

To our knowledge, this is the first study that compares MFI and quantitative RBCV. Our data show that MFI provides an appropriate index to characterize microvascular blood flow.

The effects of hemorrhagic shock on intestinal microcirculation, however, are controversial and probably strongly dependent on the used models. Nakayima et al. [31] have shown that hemorrhagic shock in mice only produces moderate effects characterized by decreased villi density without changes in blood flow velocity. On the other hand, Fruchterman et al. [8] have shown that microvascular blood flow decreased more than $70 \%$ from baseline. Similar findings were reported by Watkins et al. [9] and Zacaria et al. [32]. Our results evidenced that ileal serosal and mucosal microcirculatory blood flow velocities are progressively compromised during stepwise hemorrhage.

Good interobserver agreement has been reported for the semi-quantitative analysis of microcirculation $[17,19$, 22]. Nevertheless, Bracht et al. recently showed a poor reproducibility of this evaluation. They showed that OPS imaging only reveals changes in villi perfusion at $75 \%$ of SMA flow reduction [33]. The reasons for these different results are unclear [34]. The authors highlighted the limitations of OPS evaluation but acknowledged that the poor quality of the OPS images and the approach to quantify the microcirculation could account for it. In our study, interobserver agreement was not studied. MFI, however, was strongly correlated with actual RBCV, a measurement which is almost independent of the operator.

While previous studies were focused on the effects of severe hemorrhagic shock [8-15, 32], the present study shows intestinal microvascular alterations after less severe blood losses. Furthermore, our finding that the sublingual microcirculation also becomes impaired makes this location a potentially sensitive measurement for the non-invasive monitoring of hypovolemia.

Our findings showed that stepwise bleeding results in a progressive reduction in the microcirculatory velocities, as evaluated either by RBCVs or MFIs, in the different locations measured. In spite of this observation, there were higher decreases in capillary density and increases in heterogeneity in ileal mucosa than in ileal serosal and sublingual mucosa. In sepsis, clinical and experimental investigations have shown differential behavior between the sublingual and gut microcirculation. Boerma et al. [27] have reported, in patients with abdominal sepsis, the lack of correlation between sublingual and intestinal mucosal MFI. They also showed a disparity between skin perfusion and sublingual microcirculatory alterations in severe sepsis and septic shock [35]. In addition, Dubin et al. showed that during experimental septic shock in sheep, there are similar microvascular alterations in 
different sites. After fluid resuscitation, however, there is a distributive defect that renders the villi hypoperfused despite the normalization of systemic and intestinal blood flows, and sublingual and gut serosal microcirculation [28]. These differences may be caused by the action of regulatory mechanisms that are more severely disrupted in sepsis than during hemorrhage, resulting in shunting and a more manifest dissociation of the circulation of the various organ beds. Our data expands previous observations showing that microvascular heterogeneity is also an important feature of the microvascular response to hypovolemia [30].

The development of heterogeneity and the differences in the microcirculatory behavior between the three territories suggest that the microcirculatory findings not only are a consequence of reduced cardiac output but might also reflect distinct autoregulatory mechanisms at the tissue level.

Some studies have shown that base deficit adequately quantifies oxygen debt and correlates with lactate levels [4]. In the present study, however, the decrease in arterial $\mathrm{pH}$ and base excess was a late event.

In contrast to previous reports $[3,4,36]$, intramucosal acidosis only developed in the last step of the hemorrhage. Beyond tonometry drawbacks, reductions of blood flow might have not been enough to produce intramucosal acidosis. Reductions of SMA blood flow of 50\% from baseline are associated with only minor increases of intramucosal $\mathrm{PCO}_{2}$ measured by fiberoptic sensors [37].

Mixed and mesenteric venous $P_{2}$ and $\mathrm{O}_{2}$ saturations were progressively reduced after the first episode of hemorrhage. Nevertheless, they were only significantly different from control group in the last step of bleeding. Despite the absence of changes in $V \mathrm{O}_{2}$, lactate levels rapidly arose. The underlying mechanism is uncertain [38].
This study has several limitations. Direct measurements of volemia were not performed. Likewise, in most large animal studies, the sample size is limited. Even if the current data are significant, larger studies, possibly in clinical settings, are advocated to confirm the current findings. In addition, the microcirculation in the three territories could not be measured simultaneously. During the sequential measurements, various physiologic mechanisms triggered by the hemorrhage may influence the microcirculation over time. This might have modified the results, since the measurements were always done in the same sequence. Another potential source of bias might be the different number of vessels that the software was able to analyze according to the territory.

\section{Conclusions}

In this model of progressive hemorrhage, there were significant microcirculatory changes. These microvascular changes appeared from the first step of bleeding and not only reflect systemic alterations but might express local adjustments that exceed the changes in cardiac output. They could be adequately identified using both the easy to implement semi-quantitative MFI as well as by quantitative measurement of capillary red blood cell flow using space-time diagrams.

Conflict of interest statement Dr. Ince is Chief Scientific Officer of MicroVision Medical (an university-based company manufacturing sidestream dark-field devices) and holds patents and stock related to sidestream dark-field imaging. The remaining authors have not disclosed any potential conflicts of interest.

\section{References}

1. Crowell JW, Smith EE (1964) Oxygen deficit and irreversible hemorrhagic shock. Am J Physiol 206:313-316

2. Rivers E, Nguyen B, Havstad S, Ressler J, Muzzin A, Knoblich B, Peterson E, Tomlanovich M, Early Goal-Directed Therapy Collaborative Group (2001) Early goal-directed therapy in the treatment of severe sepsis and septic shock. N Engl J Med 345:1368-1377

3. Hamilton-Davies C, Mythen MG, Salmon JB, Jacobson D, Shukla A, Webb AR (1997) Comparison of commonly used clinical indicators of hypovolaemia with gastrointestinal tonometry. Intensive Care Med 23:276-281
4. Povoas HP, Weil MH, Tang W, Moran B, Kamohara T, Bisera J (2000) Comparisons between sublingual and gastric tonometry during hemorrhagic shock. Chest 118:1127-1132

5. Weil MH, Afifi AA (1970) Experimental and clinical studies on lactate and pyruvate as indicators of the severity of acute circulatory failure (shock). Circulation 41:989-1001

6. Davis JW, Shackford SR, Mackersie RC, Hoyt DB (1988) Base deficit as a guide to volume resuscitation. J Trauma 28:1464-1467

7. Sinaasappel $M$, van Iterson $M$, Ince $C$ (1999) Microvascular oxygen pressure in the pig intestine during haemorrhagic shock and resuscitation. J Physiol 514:245-253
8. Fruchterman TM, Spain DA, Wilson MA, Harris PD, Garrison RN (1998) Complement inhibition prevents gut ischemia and endothelial cell dysfunction after hemorrhage/ resuscitation. Surgery 124:782-791

9. Watkins JM, Spain DA, Krysztopik RJ, Downard PJ, Wilson MA, Garrison RN (1996) Heparan preserves intestinal perfusion after hemorrhage and resuscitation. J Surg Res 66:154-158

10. Zhao KS, Junker D, Delano FA, Zweifach BW (1985) Microvascular adjustments during irreversible hemorrhagic shock in rat skeletal muscle. Microvasc Res 30:143-153 
11. Colantuoni A, Bertuglia S, Intaglietta M (1985) Microvessel diameter changes during hemorrhagic shock in unanesthetized hamsters. Microvasc Res 30:133-142

12. Morini S, Yacoub W, Rastellini C, Gaudio E, Watkins SC, Cicalese L (2000) Intestinal microvascular patterns during hemorrhagic shock. Dig Dis Sci 45:710-722

13. Fang X, Tang W, Sun S, Huang L, Chang YT, Castillo C, Weil MH (2006) Comparison of buccal microcirculation between septic and hemorrhagic shock. Crit Care Med 34:S447-S453

14. Balogh Z, Wolfárd A, Szalay L, Orosz E, Simonka JA, Boros M (2002) Dalteparin sodium treatment during resuscitation inhibits hemorrhagic shock-induced leukocyte rolling and adhesion in the mesenteric microcirculation. J Trauma 52:1062-1069

15. Kerger H, Waschke KF, Ackern KV, Tsai AG, Intaglietta M (1999) Systemic and microcirculatory effects of autologous whole blood resuscitation in severe hemorrhagic shock. Am J Physiol 276:H2035-H2043

16. Goedhart PT, Khalilzada M, Bezemer R, Merza J, Ince C (2007) Sidestream Dark Field (SDF) imaging: a novel stroboscopic LED ring-based imaging modality for clinical assessment of the microcirculation. Optics Express 15:15101-15114

17. De Backer D, Creteur J, Preiser JC, Dubois MJ, Vincent JL (2002) Microvascular blood flow is altered in patients with sepsis. Am J Respir Crit Care Med 166:98-104

18. Sakr Y, Dubois MJ, De Backer D, Creteur J, Vincent JL (2004) Persistent microcirculatory alterations are associated with organ failure and death in patients with septic shock. Crit Care Med 32:1825-1831

19. Boerma EC, Mathura KR, van der Voort PHJ, Spronk PE, Ince C (2005) Quantifying bedside-derived imaging of microcirculatory abnormalities in septic patients: a prospective validation study. Crit Care 9:R601-R606

20. Dubin A, Pozo MO, Ferrara G, Murias G, Martins E, Canullán C, Canales HS, Ince C (2006) Changes in microcirculation are early indicators of hypovolemia. Intensive Care Med 32:S81
21. Dobbe JG, Streekstra GJ, Atasever B, van Zijderveld R, Ince C (2008) Measurement of functional microcirculatory geometry and velocity distributions using automated image analysis. Med Biol Eng Comput 46:659-670

22. Trzeciak S, Dellinger RP, Parrillo JE, Guglielmi M, Bajaj J, Abate NL, Arnold RC, Colilla S, Zanotti S, Hollenberg SM, Microcirculatory Alterations in Resuscitation, Shock Investigators (2007) Early microcirculatory perfusion derangements in patients with severe sepsis and septic shock: relationship to hemodynamics, oxygen transport, and survival. Ann Emerg Med 49:88-98

23. De Backer D, Hollenberg S, Boerma C, Goedhart P, Büchele G, Ospina-Tascon G, Dobbe I, Ince C (2007) How to evaluate the microcirculation: report of a round table conference. Crit Care 11:R101

24. Torrington KG, McNeil JS, Phillips YY, Ripple GR (1989) Blood volume determinations in sheep before and after splenectomy. Lab Anim Sci 39:598-602

25. American College of Surgeons, Committee on Trauma: advanced trauma life support for doctors course manual (1997), 6th edn. Chicago

26. Schadt JC, Ludbrook J (1991) Hemodynamic and neurohumoral responses to acute hypovolemia in conscious mammals. Am J Physiol 260:H305-H318

27. Boerma EC, van der Voort PH, Spronk PE, Ince C (2007) Relationship between sublingual and intestinal microcirculatory perfusion in patients with abdominal sepsis. Crit Care Med 35:1055-1060

28. Dubin A, Edul VS, Pozo MO, Murias G, Canullán CM, Martins EF, Ferrara G, Canales HS, Laporte M, Estenssoro E, Ince C (2008) Persistent villi hypoperfusion explains intramucosal acidosis in sheep endotoxemia. Crit Care Med 36:535-542

29. Deruddre S, Pottecher J, Georger J, Repéssé X, Benhamou D, Vicaut E, Teboul J, Duranteau J (2007) Sublingual microcirculatory improvement with fluid loading in preload-dependent ICU patients. Intensive Care Med 33:S253
30. Vajda K, Szabó A, Boros M (2004) Heterogeneous microcirculation in the rat small intestine during hemorrhagic shock: quantification of the effects of hypertonic-hyperoncotic resuscitation. Eur Surg Res 36:338-344

31. Nakajima Y, Baudry N, Duranteau J, Vicaut E (2001) Microcirculation in intestinal villi: a comparison between hemorrhagic and endotoxin shock. Am J Respir Crit Care Med 164:1526-1530

32. Zakaria el R, Garrison RN, Spain DA, Matheson PJ, Harris PD, Richardson JD (2003) Intraperitoneal resuscitation improves intestinal blood flow following hemorrhagic shock. Ann Surg 237:704-711

33. Bracht H, Krejci V, Hiltebrand LB, Brandt S, Sigurdsson G, Ali SZ, Takala J, Jakob SM (2008) Orthogonal polarization spectroscopy to detect mesenteric hypoperfusion. Intensive Care Med 34:1883-1890

34. Ince C (2008) The elusive microcirculation. Intensive Care Med 34:1755-1756

35. Boerma EC, Kuiper MA, Kingma WP, Egbers PH, Gerritsen RT, Ince C (2008) Disparity between skin perfusion and sublingual microcirculatory alterations in severe sepsis and septic shock: a prospective observational study. Intensive Care Med 34:1294-1298

36. Dubin A, Estenssoro E, Murias G, Canales H, Sottile P, Badie J, Baran M, Palizas F, Laporte M, Rivas Diaz M (2001) Effects of hemorrhage on gastrointestinal oxygenation. Intensive Care Med 27:1931-1936

37. Knichwitz G, Rotker J, Mollhoff T, Richter KD, Brussel T (1998) Continuous intramucosal $\mathrm{PCO}_{2}$ measurement allows the early detection of intestinal malperfusion. Crit Care Med 26:1550-1557

38. McCarter FD, James JH, Luchette FA, Wang L, Friend LA, King JK, Evans JM, George MA, Fischer JE (2001) Adrenergic blockade reduces skeletal muscle glycolysis and $\mathrm{Na}(+), \mathrm{K}(+)$ ATPase activity during hemorrhage. J Surg Res 99:235-244 